\title{
EFFECT OF HARVESTING TIME ON HEMP (Cannabis sativa L.) SEED OIL LIPID COMPOSITION
}

\author{
Silvia Marzocchi ${ }^{1}$ and Maria Caboni ${ }^{2}$ \\ ${ }^{1}$ Affiliation not available \\ ${ }^{2}$ University of Bologna
}

May 5, 2020

\begin{abstract}
The most common food using hemp (Cannabis sativa L.) is hempseed oil (HSO) because it is a rich source of nutrients and not nutrients with nutritional and functional beneficial effects for human body. Harvesting time can affect the quality of HSO, consequently the aim of this study was to evaluate the composition of lipid fraction, fatty acids, tocopherols and sterols, during ripening. Two cultivars, Futura 75 and Carmagnola, were collected at three ripening stages during August and September 2015 and their lipid composition was determined by analytical techniques. Among the fatty acid identified, the linoleic acid was the preponderant, followed by oleic, $\alpha$-linolenic and palmitic acid. Linoleic: $\alpha$-linolenic acid and polyunsaturated:saturated fatty acid ratios decreased and increased, respectively, in both varieties with ripening. $\gamma$-tocopherol was the preponderant tocopherol identified, Futura 75 showed the highest content in the middle of maturation while Carmagnola at the beginning. $\beta$-sitosterol was the predominant sterol identified in both varieties, followed by campesterol, $\Delta 5$-avenasterol, stigmasterol and $\Delta 7$-stigmasterol. Total sterol content increased and decreased with ripening in Futura 75 and Carmagnola, respectively. The study confirms that ripening stage affects the quality of hempseed oil, important parameter to consider for hemp seed producers.
\end{abstract}

\section{EFFECT OF HARVESTING TIME ON HEMP (Cannabis sativa L.) SEED OIL LIPID COMPOSITION}

Silvia Marzocchi ${ }^{\mathrm{a}}$ and Maria Fiorenza Caboni ${ }^{\mathrm{a}}$

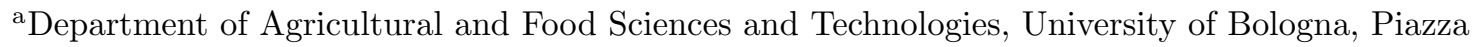

Goidanich 60, 47521 Cesena (FC), Italy

E-mail address:

Silvia Marzocchi:silvia.marzocchi4@unibo.it

Maria Fiorenza Caboni:maria.caboni@unibo.it

*Corresponding author: Silvia Marzocchi,silvia.marzocchi4@unibo.it, Fax number: +390547382348

\section{Abstract}

The most common food using hemp (Cannabis sativa L.) is hempseed oil (HSO) because it is a rich source of nutrients and not nutrients with nutritional and functional beneficial effects for human body. Harvesting time can affect the quality of HSO, consequently the aim of this study was to evaluate the composition of lipid fraction, fatty acids, tocopherols and sterols, during ripening. Two cultivars, Futura 75 and Carmagnola , were collected at three ripening stages during August and September 2015 and their lipid composition was determined by analytical techniques. Among the fatty acid identified, the linoleic acid was the preponderant, followed by oleic, $\alpha$-linolenic and palmitic acid. Linoleic: $\alpha$-linolenic acid and polyunsaturated:saturated fatty acid ratios decreased and increased, respectively, in both varieties with ripening. $\gamma$-tocopherol was the 
preponderant tocopherol identified, Futura 75 showed the highest content in the middle of maturation while Carmagnola at the beginning. $\beta$-sitosterol was the predominant sterol identified in both varieties, followed by campesterol, $\Delta_{5}$-avenasterol, stigmasterol and $\Delta_{7}$-stigmasterol. Total sterol content increased and decreased with ripening in Futura 75 and Carmagnola, respectively. The study confirms that ripening stage affects the quality of hempseed oil, important parameter to consider for hemp seed producers.

Keywords: Cannabis sativa L.; hempseed oil; fatty acids; tocopherols; sterols

\section{Introduction}

Cannabis sativa L., belonged to Cannabaceae family, is an annual plant known by its long, thin flower and spiky leaves (Montserrat-de la Paz, Marín-Aguilar, García-Giménez \& Fernández-Arche, 2014).Cannabis sativa subsp. sativa is characterized by a low content of THC ( $\Delta^{9}$-tetrahydrocannabinol), it must be lower than $0.2 \%$ on dry basis to be cultivated in most European countries (Official Journal of European Union, 2008). Industrial hemp with a low THC content has no psychoactive effects (Siudem, Wawer \& Paradowska, 2019). The most common food using hemp is hempseed oil (HSO); it is a rich source of nutrients and not nutrients that provide nutritional and functional support for humans (Crescente et al., 2018). HSO represents the 25-35\% of hemp seed (Callaway, 2004; Montserrat-de la Paz et al., 2014; Crimaldi, Faugno, Sannino \& Ardito, 2017) and it contains more than $80 \%$ of polyunsaturated fatty acids (PUFAs) (Petrović, Debeljak, Kezić \& Džidara, 2015; Siudem et al., 2019) including essential fatty acids usually not contained in oils used for human diet (Petrović et al., 2015); in particular $\omega-6$ linoleic acid (LA) and $\omega-3 \alpha$-linolenic acid (ALA). In addition, LA:ALA ratio is 3:1 which agrees with European Food Safety Agency recommendations (EFSA, 2009). HSO is composed of 1.5-2\% unsaponifiable fraction, a source of interesting minor compounds like tocopherols, fat-soluble vitamin D and E (Siudem et al., 2019) and phytosterols (Montserrat-de la Paz et al., 2014). Therefore, HSO has a lot of beneficial effects: cancer and cardiovascular disease prevention, cholesterol level normalization, blood pressure lowering (Devi \& Khanam, 2019) and rheumatoid arthritis and dermatitis treatment (Oomah, Busson, Godfrey \& Drover, 2002; Chow, 2008). For all these reasons industries are attracted by HSO for drugs, cosmetics, body care products and dietary supplement production (Callaway, 2004; Kolodziejczyk, Ozimek, Kozlowska., 2012).

To the best of our knowledge, in literature are reported only two studies about the effect of maturation on yield, quality of fiber and oil of industrial hemp. Höppner \& Menge-Hartmann (2007) studied the yield and the quality of fiber and oil of different hemp cultivars in Germany at two different harvest time ("intensive flowering" and "initial seed maturity"). The different harvest stages did not have effect on stem diameter, fiber content and yield; on the other hand, seed yield and seed oil content increased with maturation while the $\gamma$-linolenic acid content decreased. Burczyk, Grabowska, Strybe \& Konczewicz (2009) studied the effect of sowing density and date of harvest (beginning of panicle forming, full bloom and full seed maturity) on industrial hemp yields. They observed that the maximum yields of biomass, cellulose and fiber can be obtained at $30 \mathrm{~kg} /$ ha sowing density at full bloom; while considering hemp for seed or panicles the highest yields were obtained at $10-20 \mathrm{~kg} / \mathrm{ha}$ of density at full maturity of panicles.

The aim of this study was the characterization of lipid fraction of two different cultivar of Cannabis sativa L., Futura 75 and Carmagnola, harvested at three different harvest stages; in order to investigate the quality of hempseed oil during the maturation, which was never investigated before. To this end, fatty acids, tocopherols and sterols content were determined using fast chromatographic techniques, HPLC and GC equipped with different detectors.

\section{Materials and Methods}

\subsection{Fruit harvest and sample preparation}

Cannabis sativa L. seeds from two different varieties, Futura 75 and Carmagnola, were picked in Ancona area in Italy approximately $43^{\circ} 30^{\prime} 34286^{\prime \prime} \mathrm{N}, 13^{\circ} 15^{\prime} 33052^{\prime \prime}$ E. Fruits were harvested at three different harvesting stages during August and September 2015. At first harvest, Futura 75 were collected on August 26 ${ }^{\text {th }}$ (F1) and Carmagnola on September $3^{\text {rd }}(\mathrm{C} 1)$; at the second harvest, Futura 75 were collected on September $3^{\text {rd }}$ 
(F2) and Carmagnolaon September $15^{\text {th }}(\mathrm{C} 2)$; and at third harvest,Futura 75 were collected on September $15^{\text {th }}$ (F3) and Carmagnola on September $23^{\text {rd }}$ (C3). At each sampling time $20 \mathrm{~g}$ of seeds were picked; all of them were grounded before analyses.

\subsection{Oil extraction and moisture content determination}

The lipid content was obtained by grounding the samples of Cannabis sativa L. seeds $(5 \mathrm{~g})$ and the oil was extracted with $n$ - hexane in a Soxhlet apparatus according to ISO method 659:1998. The remaining solvent was removed under vacuum and the oil was taken up with $n$-hexane/isopropanol $(4: 1 \mathrm{v} / \mathrm{v})$ solution and stored at-18 degC until use. Each extraction was carried out two times for each cultivar.

Moisture content (\%) was evaluated on hemp seeds samples in an oven at $105 \mathrm{degC}$ until constant weight was receached. For each samples, 3 replicates of $3 \mathrm{~g}$ weighted were dried (AOAC, 1995).

\subsection{Fatty acid analysis}

The fatty acid composition was determined as fatty acid methyl esters (FAMEs) by capillary gas chromatography analysis after alkaline treatment (Christie, 1982). Methyl tridecanoate (C13:0, $2 \mathrm{mg} / \mathrm{mL}$ ) was used as internal standard and FAMEs were measured on a GC 2010 Plus gas chromatograph (Shimadzu Corporation, Kyoto, Japan) equipped with a flame ionisation detector (FID) and an AOC-20s auto sampler (Shimadzu Corporation), at the same conditions reported in Marzocchi, Pasini, Baldinelli \& Caboni (2018). Peak identification was accomplished by comparing peak retention time with GLC-463 standard mixture from Nu-Check (Elysian, MN, USA) and FAME 189-19 standard mixtures from Sigma-Aldrich Chemicals (St. Louis, MO, USA) and expressed as weight percentage of total FAMEs. FAMEs composition was measured in 2 replicates for each lipid extract $(n=4)$ and each analysis lasted 7 minutes.

\subsection{Tocopherols analysis}

Approximately $50 \mathrm{mg}$ of hempseed oil was dissolved in $0.5 \mathrm{ml}$ of $n$ - hexane. After homogenization, the solution was filtered through a $0.2 \mu \mathrm{m}$ nylon filter and $2.5 \mu \mathrm{l}$ was injected in a HPLC 1200 series (Agilent Technologies, Palo Alto, California, USA) equipped with a fluorimeter detector (Agilent, Palo Alto, CA, USA). The excitation wavelength was $290 \mathrm{~nm}$ and the emission wavelength was $325 \mathrm{~nm}$. The separation of tocopherols was performed by a HILIC Poroshell 120 column $(100 \mathrm{~mm} \times 3 \mathrm{~mm}$ and $2.7 \mu \mathrm{m}$ particle size; Agilent Technologies, USA), in isocratic conditions, using an $n$-hexane/ethyl acetate/acetic acid (97.3:1.8:0.9 $\mathrm{v} / \mathrm{v} / \mathrm{v}$ ) mobile phase. The flow rate was $0.8 \mathrm{ml} / \mathrm{min}$. Tocopherols were identified by co-elution with the respective standards. The calibration curve used for quantification was constructed with $\alpha$-tocopherol standard solutions. Tocopherols composition was measured in 2 replicates for each lipid extract $(n=4)$ and expressed in $\mathrm{mg} / 100 \mathrm{~g}$ of oil; each analysis lasted 8 minutes.

\subsection{Sterols determination}

In order to determine the sterols content, $0.5 \mathrm{ml}$ of dihydro-cholesterol $(2 \mathrm{mg} / \mathrm{mL})$ was added to $250 \mathrm{mg}$ of oil and saponification was conducted at room temperature (Sander, Addis, Park \& Smith, 1989). After about 20 $\mathrm{h}$, the organic fraction was washed with $10 \mathrm{ml}$ of diethyl ether and $10 \mathrm{ml}$ of water. The unsaponifiable fraction was further extracted twice with $10 \mathrm{ml}$ of diethyl ether, $10 \mathrm{ml}$ of $0.5 \mathrm{~N}$ aqueous $\mathrm{KOH}$ and $10 \mathrm{ml}$ of distilled water, respectively. The organic solvent was removed under vacuum and the unsaponifiable fraction was used for the sterols analysis. Before injection, samples were silylated according to Sweeley, Bentley, Makita \& Wells (1963) and the sterol separation was performed by GC/MS (GCMS-QP2010 Plus, Shimadzu, Tokyo, Japan) in the same chromatographic conditions reported by Cardenia, Rodriguez-Estrada, Baldacci, Savioli \& Lercker et al. (2012). Sterols identification was achieved by comparing peak mass spectra with peaks of standard mixture and by comparing them to the GC-MS data reported by Pelillo, Iafelice, Marconi \& Caboni (2003). An internal standard was used to quantify all the sterols identified in seed samples. Sterols composition was measured in 2 replicates for each lipid extract $(n=4)$ and expressed in $\mathrm{mg} / 100 \mathrm{~g}$ of oil.

\subsection{Statistical analysis}


Relative standard deviation was obtained, where appropriate, for all data collected. One-way analysis of variance (ANOVA) was evaluated using Statistica 10 software (StatSoft, Tulsa, OK, USA). The differences between the means of data for the two different cultivars at the three different harvesting stages were compared at the $5 \%$ level of significance $(p<0.05)$ using Tukey honest significant difference (HSD) test.

\section{Results and Discussion}

\subsection{Oil and moisture content}

Table 1 shows oil content of Futura 75 and Carmagnola at three different harvest stages expressed on dry basis. Futura 75 showed a significantly higher $(p<0.05)$ oil content during the second harvest stage $(29.9 \%)$ rather than the other two harvestings, $22.9 \%$ and $26.4 \%$ for the first and the third harvest, respectively. On the other hand, Carmagnola did not show any significant differences $(p<0.05)$ in oil content during maturation, in fact it was $24.5 \%, 24.8 \%$ and $24.9 \%$ at first, second and third harvest, respectively. Our results are in line, or slightly lower, with literature, Latif \& Anwar (2009), Da Porto, Decorti, Tubaro (2012) and Kostić et al. (2014) that reported an oil content of $26-32 \%, 30 \%$ and 25-29\%, respectively. The lower oil content may be attributed to cultivation techniques and climatic conditions; in addition, seeds were covered by a green skin that certainly influenced the oil content, since it covered completely the seed.

As regard moisture (Table 1), an expected reduction in percentage of moisture was recorded in both varieties with the increasing of maturation; it is well known that immature seeds contain a higher water content rather than mature seeds (Matthäus \& Brühl, 2006). Futura 75 starting from a moisture value of $50 \%$ at F1, that decreased significantly $(p<0.05)$ at F2 $(32 \%)$ reaching a final value of $20 \%$ at full maturity. Moisture content in Carmagnolahad the same trend, starting from a value of $31 \%$ at $\mathrm{C} 1$ and decreasing significantly $(p<$ $0.05)$ at $\mathrm{C} 2(17 \%)$ and finally at C3 (10\%). Moisture value reported in various studies, Oomah et al. (2002), Tang, Ten, Wang \& Yang (2006) and Da Porto et al. (2012), are much lower than ours; in fact, they reported values of $7.7,6.7$ and $7.8 \%$, respectively. This could be due to the green skin, as previously mentioned, that covered the seeds that certainly had a high impact on moisture content. Sacilik, Öztürk \& Keskin (2006) conducted a study on physical properties of hemp seeds (size, density and porosity) as a function of moisture content and found out values more similar to ours (ranging from 8.6 to $20.9 \%$ ).

\subsection{Fatty acid profile}

A total of 17 and 15 fatty acids in Futura 75 and in Carmagnola, respectively, were identified and quantified by fast GC-FID analysis, within a run time less than 7 minutes. As showed in Table 2, the predominant fatty acid in all samples was linoleic acid (C18:2, $\omega-6)$, ranging from about 49 to $54 \%$. Oleic acid (C18:1cis9 ) was the second major fatty acid detected ( $15-16 \%)$, followed by $\alpha$-linolenic acid (C18:3, $\omega-3, \sim 12-15 \%)$, palmitic acid (C16:0, 7-9 \%), stearic acid (C18:0, 2-3\%) and $\gamma$-linolenic acid (C18:3, $\omega-6, \sim 2-3 \%)$.

In Futura 75 , the saturated fatty acids (SFA) were present in significantly $(p<0.05)$ greater amount at the first harvesting time (16.7\%), whereas mono-unsaturated fatty acids (MUFA) did not showed significant differences among the three different harvest stages ( $18.7 \%, 18.3 \%$ and $18.1 \%$ for F1, F2 and F3, respectively). Polyunsaturated fatty acids (PUFA), on the other hand, increased significantly $(p<0.05)$ their concentration with hemp maturation, accounting for $64.6 \%, 69.6 \%$ and $69.6 \%$ for F1, F2 and F3, respectively. These trends reflect those of the main fatty acid: in fact, PUFA was the most abundant class because of linoleic acid concentration. In Carmagnola, SFA had a significantly higher $(p<0.05)$ concentration at first harvest stage (12.2\%), than the other two (11.8\% and $11.6 \%$ in C2 and C3, respectively); while MUFA did not show significant differences between first and third harvest stages (18.2\% and $18.0 \%$, respectively), with a slightly decrease in the middle stage $(16.7 \%)$. PUFA, on the contrary, showed a significant increase $(p<0.05)$ at the second harvest stage (71.6\%), between first and third harvestings (69.7\% and 70.5\%). Comparing our results with literature, SFA content is generally higher than data already reported for hemp native from Italy (7\%, Da Porto et al., 2012) and from other countries like Croatia (9-11\%, Petrović et al., 2015), Spain (11\%, Montserrat-de la Paz et al., 2014) and Turkey (9-10\%, Kiralan, Gül \& Metin Kara, 2010); this because of palmitic and stearic acid content that is higher than reported literature. Only in a study conducted by Devi \& Khanam (2019) is reported a similar concentration of palmitic acid compared to our results, $10 \%$ referred 
to hemp cultivated in India. MUFA content was higher in our study than literature; $12-16 \%$ (Kiralan et al., 2010), 11\% (Da Porto et al., 2012), 13\% (Montserrat-de la Paz et al., 2014) and 10-14\% (Petrović et al., 2015). This because of oleic acid, that represent almost the entire MUFA content. On the contrary, PUFA determined in this study was lower than the already cited literature; in fact, Kiralan et al. (2010) showed a 73-78\%; Da Porto et al. (2012) a 80-81\%, Montserrat-de la Paz et al. (2014) a 75\% and Petrović et al. (2015) a 74-80\%. For this reason, the ratio between unsaturated and saturated fatty acids reported in our study, 3-5 in Futura 75 and 5-6 in Carmagnola is slightly lower than that reported in literature (6,7 showed by Montserrat-de la Paz et al., 2014). In general, this characteristic high ratio between unsaturated and saturated fatty acids can reduce serum cholesterol and atherosclerosis; and prevent heart diseases (Reena \& Lokesh, 2007). On the other hand, because of its high unsaturation level and susceptibility to oxidation, hemp seeds oil has a short shelf life (Kiralan et al., 2010) and it is not suitable for hot uses (Da Porto et al., 2012).

As regard to the ratio between the two essential polyunsaturated fatty acids, linoleic and $\alpha$-linolenic acid, both varieties, Futura 75and Carmagnola, showed the highest value at the first harvest, 4.05 and 3.90, respectively (Table 2). This even though linoleic and $\alpha$-linolenic acids did not have the same trend in the two different varieties. In Futura 75 linoleic acid showed a significant $(p<0.05)$ increase from the beginning to the end of maturation $(49.2 \%, 52.3 \%$ and $52.5 \%$ for F1, F2 and F3); in Carmagnola, instead, its concentration increased significantly $(p<0.05)$ from first $(53.7 \%)$ to second harvest $(54.7 \%)$ and then decreased again at the third harvest stage (53.9\%). $\alpha$-linolenic acid, instead, in Futura 75 increased significantly $(p<0.05)$ between first (12.1\%) and second harvest (14.3\%), before decreased again at third harvest stage (13.9\%); in Carmagnola its concentration increased significantly during all the maturation; $13.8 \%, 14.6 \%$ and $14.9 \%$ for $\mathrm{C} 1, \mathrm{C} 2$ and $\mathrm{C} 3$, respectively. The high quantity of $\alpha$-linolenic acid improves hemp oil quality for its positive nutritional implications and beneficial effects against coronary disease and cancer (Arshad, AlLeswas, Stephenson, Metcalfe \& Dennison, 2011; Fretts et al., 2013). In general, our results about these two fatty acids are slightly lower than results in literature. In fact linoleic acid content is reported in a range between 48 and 59\% and $\alpha$-linolenic acid in a range between 16 and 26\% (Montserrat-de la Paz et al., 2014; Orsanova, Misurcova, Ambrozova, Vicha \& Mlcek, 2015; Petrović et al., 2015; Mikulcová, Kašpárková, Humpolíček \& Buňková, 2017; Devi \& Khanam, 2019; Siudem et al., 2019).

\subsection{Tocopherols}

The individual tocopherols identified are showed in Table 3 ; a total of $49.8,86.9$ and $41.2 \mathrm{mg} / 100 \mathrm{~g}$ of oil were quantified in F1, F2 and F3, respectively; while a total of $94.8,87.7$ and $77.8 \mathrm{mg} / 100 \mathrm{~g}$ of oil were quantified in C1, C2 and C3, respectively. It is recognized that tocopherols are the most important natural antioxidants because of their free radical scavenge activity, involving a tocopherol-tocopheryl semiquinone redox system (Montserrat-de la Paz et al., 2014). In addition they have shown different beneficial effects on degenerative diseases such as atherosclerosis, cardiovascular disease, Alzheimer's disease and certain type of cancer (Fromm, Bayha, Kammerer \& Carle, 2012).

As expected, considering the literature, in all samples $\gamma$-tocopherol was the predominant compound followed by $\beta$-tocopherol, $\alpha$-tocopherol and $\alpha$-tocotrienol. In Futura $75 \gamma$-tocopherol showed a significative increase $(p$ $<0.05)$ between first and second harvest (40.8 and $82 \mathrm{mg} / 100 \mathrm{~g}$ of oil in F1 and F2, respectively) and then significantly $(p<0.05)$ decrease at last maturation time $(\mathrm{F} 3,37.1 \mathrm{mg} / 100 \mathrm{~g}$ of oil). The other tocopherols were present in very low concentration; in fact, $\beta$-tocopherol was present only at the first harvesting stage $(9.0$ $\mathrm{mg} / 100 \mathrm{~g}$ of oil) and $\alpha$-tocotrienol just in the last one $(3.3 \mathrm{mg} / 100 \mathrm{~g}$ of oil). $\alpha$-tocopherol were not detected at first maturation stage, but only in the other two, with a significative $(p<0.05)$ decrease between them, 4.9 and $0.8 \mathrm{mg} / 100 \mathrm{~g}$ of oil for F2 and F3, respectively. For this reason, the total tocopherols content had the same trend of $\gamma$-tocopherol, increasing significantly $(p<0.05)$ the total concentration at the second harvest stage (F2) reaching a value about $87 \mathrm{mg} / 100 \mathrm{~g}$ of oil (Table 3). Also in Carmagnola $\gamma$-tocopherol was the predominant tocopherol with a significative decrease $(p<0.05)$ during the maturation, 90.2, 81.8 and $72.9 \mathrm{mg} / 100 \mathrm{~g}$ of oil for F1, F2 and F3, respectively. $\beta$-tocopherol, on the contrary, was not detected during the entire maturation. $\alpha$-tocopherol was present in every maturity stage with a significant increase $(p$ 
$<0.05)$ in the middle of maturity; 3.5, 5.9 and $4.9 \mathrm{mg} / 100 \mathrm{~g}$ of oil in C1, C2 and C3, respectively. Finally, $\alpha$-tocotrienol was present just at the beginning of maturity (C1) with a concentration of $1.1 \mathrm{mg} / 100 \mathrm{~g}$ of oil. Total tocopherol concentration follows $\gamma$-tocopherol trend, so a constant significative decrease during maturation was recorded; 94.8, 87.7 and $77.8 \mathrm{mg} / 100 \mathrm{~g}$ of oil in $\mathrm{C} 1, \mathrm{C} 2$ and $\mathrm{C} 3$, respectively.

Our results agree with literature where $\gamma$-tocopherol represent the $90 \%$ of the total tocopherols content (Oomah et al., 2002; Anwar, Latif \& Ashraf, 2006; Latif \& Anwar, 2009; Montserrat-de la Paz et al., 2014). In a study conducted by Kriese et al. (2004), where hempseed oil was extracted by supercritical fluids, the general tocopherol content was much lower than ours, so, in addition to botanical characteristics, climatic and cultivation conditions, also the extraction method affects the tocopherols content.

\subsection{Sterols}

Analysis of the trimethylsilyl derivatives of phytosterols, applying GC-MS, led to identify nine compounds in both varieties of Cannabis sativa L. such campesterol, campestanol, stigmasterol, clerosterol, $\beta$-sitosterol, sitostanol, $\Delta_{5^{-}}$avenasterol, $\Delta_{5}$-24-stigmastadienol and $\Delta_{7}$-stigmasterol (Table 4 ). The total sterols content showed different trend in the two varieties of Cannabis sativa L. considered; in fact, it significantly increased $(p<0.05)$ in Futura 75 during maturation $(642.8,679.1$ and $913.4 \mathrm{mg} / 100 \mathrm{~g}$ of oil in F1, F2 and F3, respectively) and, on the other hand, significantly decreased in Carmagnola $(532.7,518.7$ and $456.1 \mathrm{mg} / 100$ $\mathrm{g}$ of oil in $\mathrm{C} 1, \mathrm{C} 2$ and $\mathrm{C} 3$, respectively). These trends reflect the $\beta$-sitosterol trends, the predominant sterol detected. In fact, it represented the $63 \%$ of the total content in both varieties, but its concentration significantly increased and decreased inFutura 75 and Carmagnola, respectively, with maturation (Table 4). In Futura 75 it had an initial increase about $5 \%$ from F1 to $\mathrm{F} 2$ and about $36 \%$ between $\mathrm{F} 2$ and $\mathrm{F} 3$; in Carmagnola, on the other hand, $\beta$-sitosterol decrease about $6 \%$ from first to second harvest stage and then, again about $10 \%$, between second and third harvest.

In Futura 75 campesterol, campestanol, stigmasterol and clerosterol had the same trend reported for $\beta$ sitosterol; instead the other sterols detected decreased between the first and the second harvest stage and then increased at full maturity (Table 4). InCarmagnola, instead, campesterol and clerosterol decreased significantly $(p<0.05)$ during the maturation; campestanol and stigmasterol did not show significant differences during the three harvesting stages.

To the best of our knowledge, only Montserrat-de la Paz et al. (2014) reported a study of sterols in hemp seed oil. Our results were higher than what is reported by these authors for Spanish hempseed oil (total content of $279.4 \mathrm{mg} / 100 \mathrm{~g}$ of oil) but $\beta$-sitosterol $(190.5 \mathrm{mg} / 100 \mathrm{~g}$ of oil) and campesterol $(50.6 \mathrm{mg} / 100 \mathrm{~g}$ of oil) were the same predominant sterols. Comparing sterols composition of HSO with other oils it is possible to see some differences. Considering other vegetable oils, olive oil, linseed oil and hazelnut oil contain an higher amount of campesterol, $\beta$-sitosterol and $\Delta_{5}$-avenasterol than HSO. Campesterol reachs values of 40 , $50-95,785 \mathrm{mg} / \mathrm{kg}$; stigmasterol values of $20,10-18,343 \mathrm{mg} / \mathrm{kg} ; \beta$-sitosterol values of $750,1050-1700,1600$ $\mathrm{mg} / \mathrm{kg}$ and $\Delta_{5}$-avenasterol value of 40-140, 20-80,369 mg/kg in olive oil, hazelnut oil (Azadmard-Damirchi \& Torbati, 2015) and linseed oil (Matthäus \& Özcan, 2017), respectively. In addition, linseed oil contains cholesterol, brassicasterol and 5,24-stigmasterol that are not present in HSO. On the other hand, HSO is richer in sterols that sunflower oil, in fact campesterol, stigmasterol, $\beta$-sitosterol and $\Delta_{5}$-avenasterol report value of 20, 28, 186 and $20 \mathrm{mg} / 100 \mathrm{~g}$, respectively (Yilmaz \& Erden, 2019). Corn oil has the same stigmasterol content of HSO (about $33 \mathrm{mg} / 100 \mathrm{~g}$ ); is poorer in $\beta$-sitosterol than HSO (266 mg/100 g) and, on the other hand, is richer in campesterol (191mg/100g) (Yang et al., 2018).

In general, even if sterols are minor constituents of vegetable oils and are present in the unsaponifiable fraction (Gusakova, Sagdullaev \& Khushbaktova, 1998), it is well known that they have a lot of beneficial effects on human health. In fact, they can reduce the serum level of cholesterol concentration, atherosclerotic risk (Ntanios, van de Kooij, de Deckere, Duchateau \& Trautwein et al., 2003; Patel \& Thompson, 2006), low-density lipoprotein cholesterol and they are related to a lower risk of myocardial infarction (Klingberg et al., 2013).

\section{Conclusions}


This study confirms that ripening stage affects the quality of hempseed oil extracted from Cannabis sativa L.; oil content was constant during the maturity and moisture content decreased constantly; essential fatty acids (LA and ALA) increased with ripening while tocopherols decreased. Sterols showed a different trend in the two varieties considered, in Futura 75 the total concentration increased and in Carmagnola decreased. Knowledge of the influence of ripening stage on hempseed oil quality has important consequences for industrial output, as harvest could be programmed when oil, tocopherols and sterols are most abundant. Futura 75 seemed to have a higher concentration of oil, sterols and LA/ALA ratio; while Carmagnolaa higher concentration of tocopherols and PUFA/SFA ratio. The comparison between the two varieties and the results obtained are very important for hemp seeds producers since they can choose the best variety to plant from a production and quality point of view

\section{AKNOWLEDGEMENT}

The authors are grateful to Dr. Itzhak Moreno and the company "Az. Agraria Trionfi Honorati Giuseppe e Giovanna \& C." for the seeds samples used in this study.

This research did not receive any specific grant from funding agencies in the public, commercial, or not-forprofit sectors

\section{Reference}

1. Anwar, F., Latif, S., \& Ashraf, M. (2006). Analytical characterization of hemp (Cannabis sativa) seed oil from different agro-ecological zones of pakistan. Journal of the American Oil Chemists' Society, 83 :323-329.

2. AOAC. (1995). Official methods of analysis. 479 Washington. DC. USA: Association of Official Analytical Chemists.

3. Arshad, A., Al-Leswas, D., Stephenson, J., Metcalfe, M., \& Dennison, A. (2011). Potential application of fish oil rich in $\omega-3$ fatty acids in the palliative treatment of advanced pancreatic cancer. British Journal of Nutrition, $106: 795-800$.

4. Azadmard-Damirchi, S., \& Torbati, M. (2015). Adulterations in some edible oils and fats and their detection methods. Journal of Food Quality and Hazards Control, 2 :38-44.

5. Burczyk, H., Grabowska, L., Strybe, M., \& Konczewicz W. (2009). Effect of sowing density and date of harvest on yields of industrial hemp. Journal of Natural Fibers, 6 :204-218.

6. Callaway, J.C. (2004). Hempseed as a nutritional resource: an overview. Euphytica, 140 :65-72.

7. Cardenia, V., Rodriguez-Estrada, M. T., Baldacci, E., Savioli, S., \& Lercker, G. (2012). Analysis of cholesterol oxidation products by fast gas chromatography/mass spectrometry. Journal of Separation Science, $\mathbf{3 5}: 424-430$.

8. Chow, C.K. (2008). Fatty acids in food and their health implications ( $3^{\text {rd }}$ ed.) New York:Marcel Dekker.

9. Christie, W. W. (1982). A simple procedure for rapid trans-methylation of glycerolipids and cholesteryl esters. The Journal of Lipid Research, 23 :1072-1075.

10. Crescente, G., Piccolella, S., Esposito, A., Scognamiglio, M., Fiorentino, A., \& Pacifico, S. (2018). Chemical composition and nutraceutical properties of hempseed: an ancient food with actual functional value. Phytochemistry Reviews, $17: 733-749$.

11. Crimaldi, M., Faugno, S., Sannino, M., \& Ardito, L. (2017). Optimization of hemp seeds (Cannabis sativa L.) oil mechanical extraction. Chemical Engineering Transactions, 58 :373-378.

12. Da Porto, C., Decorti, D., \& Tubaro, F. (2012). Fatty acid composition and oxidation stability of hemp (Cannabis sativa L.) seed oil extracted by supercritical carbon dioxide. Industrial Crops and Products, $36: 401-404$.

13. Devi, V., \& Khanam, S. (2019). Study of $\omega-6$ linoleic and $\omega-3 \alpha$-linolenic acids of hemp (Cannabis sativa) seed oil extracted by supercritical $\mathrm{CO}_{2}$ extraction: $\mathrm{CCD}$ optimization. Journal of Environmental Chemical Engineering, $7: 102818$.

14. EFSA. (2009). Scientific opinion of the panel on the dietetic products, nutrition and allergies on a request from European Commission related to labelling reference intake values for n-3 and n- 6 
polyunsaturated fatty acids. The EFSA Journal, 1176, 1-11.

15. Fretts, A. M., Mozzafarian, D., Siscovick, D. S., Heckbert, S. R., McKnight, B., King, I. B., Rimm, E. B., Psaty, B. M., Sacks, F. M., Song, X., Spiegelman, D., \& Lemaitre, R. N. (2013). Associations of plasma phospholipid and dietary $\alpha$-linolenic acid with incident atrial fibrillation in older adults: the cardiovascular health study. Journal of the American Heart Association, 2 :e003814.

16. Fromm, M., Bayha, S., Kammerer, D. R., \& Carle, R. (2012). Identification and quantification of carotenoids and tocopherols in seed oils recovered from different Rosaceae species. Journal of Agricultural and Food Chemistry, 60 :10733-10742.

17. Gusakova, S. D., Sagdullaev, S. S., \& Khushbaktova, Z. A. (1998). Lipophilic extracts in phytoterapy and phytocosmetics: production and biological properties. Chemistry of Natural Compounds, 34 (4) :411-419.

18. Höppner, F., \& Menge-Hartman, U. (2007). Yield and quality of fibre and oil of fourteen hemp cultivars in Northern Germany at two harvest dates. Landbauforschung Völkenrode, 57 (3) :219-232.

19. ISO. (1999). International Standard ISO 659: 1998 Oilseeds Determination of Hexane Extract (or Light Petroleum Extract). Called Oil Content. ISO. Geneva. Switzerland.

20. Kiralan, M., Gül, V., \& Metin Kara, Ş. (2010). Fatty acid composition of hempseed oils from different locations in Turkey. Spanish Journal of Agricultural Research, 8 (2) :385-390.

21. Klingberg, S., Ellegård, L., Johansson, I., Jansson, J. H., Hallmans, G., \& Winkvist, A. (2013). Dietary intake of naturally occurring plant sterols is related to a lower risk of a first myocardial infarction in men but not in woman in northern Sweden. The Journal of Nutrition, 143 :1630-163.

22. Kolodziejczyk, P., Ozimek, L., \& Kozlowska, J. (2012). The application of flax and hemp seeds in food, animal feed and cosmetics production. Handbook of Natural Fibres, 2 :329-366.

23. Kostić, M. D., Nataša, M. J., Stamenković, O. S., Rajković, K. M., Milić, P. S., \& Veljković, V. B. (2014). The kinetics and thermodynamics of hempseed oil extraction by n-hexane. Industrial Crops and Products, 52 :679-686.

24. Kriese, U., Schumann, E., Weber, W. E., Beyer, M., Brűhl, L., \& Matthäus, B. (2004). Oil content, tocopherol composition and fatty acid pattern of the seeds of 51 Cannabis sativa L. genotypes. Euphytica, $137: 339-351$.

25. Latif, S., \& Anwar, F. (2009). Physicochemical studies of hemp (Cannabis sativa) seed oil using enzymeassisted cold-pressing. European Journal of Lipid Science and Technology,111 :1042-1048.

26. Marzocchi, S., Pasini, F., Baldinelli, C., \& Caboni. M. F. (2018). Value-addition of beef meat byproducts: lipid characterization by chromatographic techniques. Journal of Oleo Science,67:143-150.

27. Matthäus, B., \& Brühl, L. (2006). Virgin hemp seed oil: an interesting niche product. European Journal of Lipid Science and Technology. $110: 655-661$.

28. Matthäus, B., \& Özcan, M. M. (2017). Fatty acid composition, tocopherol and sterol contents in linseed (Linum usitatissimum L.) varieties. Journal of Chemistry and Chemical Engineering, 36 (3) :147-152.

29. Mikulcová, V., Kašpárková, V., Humpolíček, P., \& Buňková, L. (2017). Formulation, characterization, and propertiesof hemp seed oil and its emulsions. Molecules, $22: 700$.

30. Montserrat-de la Paz, S., Marín-Aguillar, F., García-Giménez, M. D., \& Fernández-Arche, M. A. (2014). Hemp (Cannabis sativa L.) seed oil: analytical and phytochemical characterization of the unsaponifiable fraction. Journal of Agricultural and Food Chemistry,62 :1105-1110.

31. Ntanios, F. Y., van de Kooij, A. J., de Deckere, E. A. M., \& Duchateau, G. S. M. J. E., Trautwein, E.A. (2003). Effects of various amount of dietary plants sterol ester on plasma and hepatic sterol concentration and aortic foam cell formation of cholesterol-fed hamsters. Atherosclerosis, 169 (1) $: 41-50$.

32. Official Journal of European Union. (2008). Commission Regulation (EC) No. 1124/2008 of 12 November 2008.

33. Oomah, D. B., Busson, M., Godfrey, D. V., \& Drover, J. C. G. (2002). Characteristics of hemp (Cannabis sativa L.) seed oil. Food Chemistry, $76: 33-43$.

34. Orsanova, J., Misurcova, L., Ambrozova, J. V., Vicha, R., \& Mlcek, J. (2015). Fatty acids composition of vegetable oils and its contribution to dietary energy intake and dependence of cardiovascular mortality 
on dietary intake of fatty acids. International Journal of Molecular Science, 16 :12871-12890.

35. Patel, M. D., \& Thompson, P. D. (2006). Phytosterols and vascular disease. Atherosclerosis, 186 (1) :12-19.

36. Pelillo, M., Iafelice, G., Marconi, E., \& Caboni, M. F. (2003). Identification of plant sterols in hexaploidy and tetraploid wheats using gas chromatography with mass spectrometry. Rapid Communication in Mass Spectrometry, $17: 2245-2252$.

37. Petrović, M., Debeljak, Ž., Kezić, N., \& Džidara, P. (2015). Relationship between cannabinoids content and composition of fatty acids in hempseed oils. Food Chemistry, 170 :218-225.

38. Reena, M. B., \& Lokesh, B. R. (2007). Hypolipidemic effects of oil with balanced amounts of fatty acids obtained by blending and interesterification of coconut oil with rice bran oil or sesame oil. Journal of Agricultural and Food Chemistry, 55 :10461-10469.

39. Sacilik, K., Öztürk, R., \& Keskin, R. (2006). Some physical properties of hemp seed. Biosystems Engineering, 86 (2) :1191-198.

40. Sander, B. D., Addis, P. B., Park, S. W., \& Smith, D. E. (1989). Quantification of cholesterol oxidation products in a variety of foods. Journal of Food Protection, 2 :109-114.

41. Siudem, P., Wawer, I., \& Paradowska, K. (2019). Rapid evaluation of edible hemp oil quality using NMR and FT-IR spectroscopy. Journal of Molecular Structure, $1177: 204-208$.

42. Sweeley, C. C., Bentley, R., Makita, M., \& Wells, W. W. (1963). Gas liquid chromatography of trimethylsilyl derivates of sugar and related substances. Journal of the American Oil Chemists' Society,85 :2497-2507.

43. Tang, C. E., Ten, Z., Wang, X. S., \& Yang, X. Q. (2006). Physicochemical and functional properties of hemp (Cannabis sativa L.) protein isolate. Journal of Agricultural and Food Chemistry,54 :8945-8950.

44. Yang, R., Zhang, L., Li, P., Yu, L., Mao, J., Wang, X., \& Zhang, Q. (2018). A review of chemical composition and nutritional properties of minor vegetable in China. Trends in Food Science and Technology, $74: 26-32$.

45. Yilmaz, E., \& Erden, A. K. (2019). Purification of degummed crude sunflower oil with selected metalorganic frameworks as adsorbents. Grasas y Aceites, 70 (4), e323.https://doi.org/10.3989/gya.0930182

Hosted file

Tables.docx available at https://authorea.com/users/302057/articles/432004-effect-ofharvesting-time-on-hemp-cannabis-sativa-l-seed-oil-lipid-composition 